\section{POS0821 THE DIFFERENT SUBTYPES OF GIANT CELL ARTERITIS BY ULTRASOUND: RESULTS FROM A FAST-TRACK CLINIC}

I. Monjo ${ }^{1}$, E. Fernández-Fernández ${ }^{1}$, J. Ortega ${ }^{2}$, E. De Miguel' ${ }^{1}{ }^{1}$ La Paz University Hospital, Rheumatology, Madrid, Spain; ${ }^{2}$ Universidad Autónoma de Madrid, School of Medicine, Madrid, Spain

Background: Giant cell arteritis (GCA) is a vasculitis that affects the medium and large vessels (LV). Although cranial artery involvement is better known, awareness of the importance of LV involvement is increasing. Imaging techniques currently constitute the basis for the diagnosis of LV-GCA and have improved its diagnosis and prevalence. In recent years, differences in clinical patterns and different inflammatory and etiopathogenic mechanisms of the disease have been suggested. Therefore, improving sensitivity to diagnosis is essential to improve the knowledge and care of our population.

Objectives: The aim of this study was to know the prevalence of the different ultrasound patterns of GCA in our area.

Methods: Retrospective records of available data were collected from all patients referred to our ACG fast track clinic in the past three years. The clinical and laboratory characteristics were evaluated at the time of referral. All patients underwent an ultrasound scan of cranial vessels (superficial temporal arteries (TA) and their frontal and parietal branches) and large vessels (axillary, subclavian and carotid arteries). The doctor confirmed the GCA diagnosis after at least six months of follow-up. The OMERACT definitions of halo sign with a hypoechoic wall thickness $\geq 0.34 \mathrm{~mm}$ were used for TA pathology for the ultrasound diagnosis of GCA and for axillary, subclavian and carotid arteries and homogeneous hypoechoic thicknesses $\geq 1 \mathrm{~mm}$ of the arterial wall were applied. Atherosclerosis lesions were evaluated to detect this disease as a possible false positive halo sign. An Esaote Mylab Twice with a $13 \mathrm{MHz}$ probe in BT and $22 \mathrm{MHz}$ for cranial vessels in 2017-2019 and an Esaote Mylab X8plus with a $15 \mathrm{MHz}$ probe for $\mathrm{BT}$ and a $24 \mathrm{MHz}$ probe for cranial arteries in 2019-2020 were used by two rheumatologist with long experience in ACG ultrasound.

Results: A total of 261 patients ( 180 women / 81 men) with suspected GCA were evaluated in our fast track clinic. The mean age $( \pm S D)$ was $76 \pm 9.2$ years and CRP at diagnosis was $75.7 \pm 68.6 \mathrm{mg} / \mathrm{L}$. The time elapsed since the first symptoms was less than $6,6-12,12-24$ or $>24$ weeks in $37.5 \%, 19.9 \%$, $12.3 \%$ and $15.7 \%$ respectively. Of the 261 cases explored, 160 had GCA, of which 102 were women and 58 men, and had a mean age of $77.21 \pm 7.9$ years. The ultrasound patterns of GCA were: 71 patients had exclusive involvement of the TA (cranial-GCA), 54 had a mixed pattern with involvement of both TA and LV (mixed-CGA), and 35 had isolated involvement of the LV (LV-GCA). That is, 125 patients had cranial involvement with or without LV involvement and 89 had LV-GCA associated or not with cranial involvement (Figure 1).

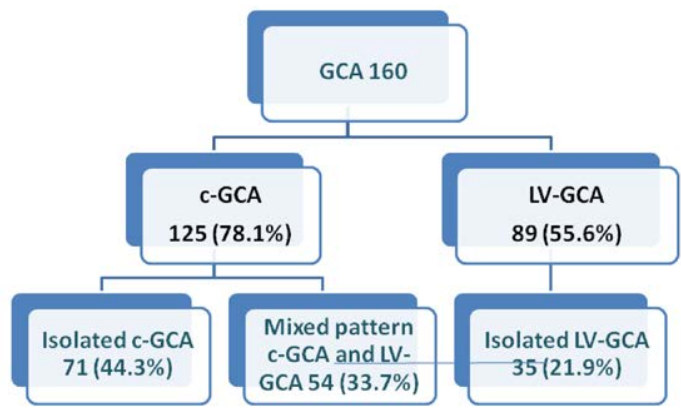

$G C A=$ Giant Cell Arteritis; $C-G C A=C$ ranial Giant Celll Arteritis; $L V-G C A=$ Large Vessell Giant Cell Arteritis Figure 1. Ultrasound patters of GCA

Conclusion: Ultrasound is a useful tool for the screening of GCA and its different subtypes of vascular involvement. The isolated cranial subtype or associated with LV-GCA is the most common (78\% of cases), but LV-GCA is also very common ( $55.6 \%$ of cases of GCA) and $21.9 \%$ presents as an isolated LV-GCA standard. The LV arteries should be included in the ultrasound examination for suspected GCA.

Disclosure of Interests: Irene Monjo Speakers bureau: Roche, Novartis, UCB, Gedeon Richter, Consultant of: Roche, Elisa Fernández-Fernández: None declared, Javier Ortega: None declared, Eugenio de Miguel Speakers bureau: AbbVie, Novartis, Pfizer, MSD, BMS, UCB, Roche, Grunental, Janssen, Sanofi, Paid instructor for: Janssen, Novartis, Roche, Consultant of: AbbVie, Novartis, Pfizer, Galapagos, Grant/research support from: Abbvie, Novartis, Pfizer DOI: 10.1136/annrheumdis-2021-eular.4154

\section{Vasculitis - small vessel vasculitis}

\begin{tabular}{l|l}
\hline POS0822 & NEW FACES OF POLYARTERITIS NODOSA: \\
& 18F-FLUORODEOXYGLUCOSE POSITRON EMISSION \\
& TOMOGRAPHY FINDINGS IN A SERIES OF 10 \\
& PATIENTS
\end{tabular}

C. Rousselin ${ }^{1}$, T. Machet ${ }^{1}$, G. Collet ${ }^{2}$, T. Quéméneur ${ }^{1}$, R. Ben Ticha ${ }^{2}$, M. Verstraete ${ }^{2}$, N. Le Gouellec ${ }^{1}$, F. Demailly ${ }^{2}$, A. Fagart ${ }^{2} .{ }^{1}$ Hôpital de Valenciennes, Internal Medicine and Nephrology, Valenciennes, France;

${ }^{2}$ Hôpital de Valenciennes, Nuclear Medicine, Valenciennes, France

Background: ${ }^{18} \mathrm{~F}$-fluorodeoxyglucose positron emission tomography with computed tomography (FDG-PET/CT) is widely used in patients with large-vessel vasculitis (1). The benefits of FDG-PET/CT in polyarteritis nodosa (PAN) has only been assessed in a few case reports (2-3).

Objectives: Our aim was to describe FDG-PET/CT findings in 10 patients with newly diagnosed PAN.

Methods: This was a retrospective study of patients with PAN who underwent FDG-PET/CT at the time of diagnosis, between 2017 and 2020. The FDG-PET/ CT data were analysed retrospectively and compared with clinical, biological, histological and conventional imaging data.

Results: Ten patients were included: 9 men and 1 woman, median age of 67 (43-78) years. PAN was diagnosed according to ACR criteria (6) in 9 patients, and histologically in the remaining patient. The clinical manifestations were: systemic $(n=10)$, muscular $(n=6)$, joint $(n=3)$, skin $(n=3)$, peripheral nervous system $(n=3)$, and gastrointestinal $(n=2)$. All patients had high C-reactive protein levels (median, $223 \mathrm{mg} / \mathrm{L}$ ). One patient had incomplete FDG-PET exploration. Three patients had begun corticosteroid therapy before their FDG-PET/CT scan. The main FDG-PET/CT abnormality was increased tracer uptake in the muscles, particularly in the connective tissue (perimysium, epimysium) $(n=7)$, in linear $(n=5)$ or focal $(n=2)$ patterns. Increased FDG uptake in large-diameter vessels was observed in 4 patients, in the humeral $(n=4)$, femoral $(n=1)$ and the common interosseous $(n=1)$ arteries. Nine patients had bone-marrow FDG uptake, six had splenic FDG uptake. Three patients had synovitis. Three had lymph-node uptake. One patient had subcutaneous FDG uptake, with a "leopard skin" appearance.

Conclusion: FDG-PET/CT seems to be a useful non-invasive imaging technique for diagnosing PAN, particularly in patients with non-specific systemic features. Tracer uptake in muscular connective tissue seems to be a recurrent sign in patients with PAN.

\section{REFERENCES:}

[1] Prieto-González S, Depetris M, García-Martínez A, Espígol-Frigolé G, Tavera-Bahillo I, Corbera-Bellata $\mathrm{M}$ et al. Positron emission tomography assessment of large vessel inflammation in patients with newly diagnosed, biopsy-proven giant cell arteritis: a prospective, case-control study. Ann Rheum Dis. 2014;73(7):1388-92.

[2] Mino N, Yamashita H, Takahashi Y, Kaneko H. Polyarteritis Nodosa With Reversible FDG Accumulation in Vessels and Kidneys. Clin Nucl Med. 2019;44(11):889-891.

[3] Schollhammer R, Schwartz P, Jullie ML, Pham-Ledard A, Mercie P, Fernandez P et al. 18F-FDG PET/CT Imaging of Popliteal Vasculitis Associated With Polyarteritis Nodosa. Clin Nucl Med. 2017;42(8):e385-e387.

[4] Lightfoot RW Jr, Michel BA, Bloch DA, Hunder GG, Zvaifler NJ, McShane DJ et al. The American College of Rheumatology 1990 criteria for the classification of polyarteritis nodosa. Arthritis Rheum. 1990;33(8):1088-93.

Disclosure of Interests: None declared

DOI: 10.1136/annrheumdis-2021-eular.120

\section{\begin{tabular}{|l|l}
\hline POS0823 ARTHRITIS IN ADULT IGA VASCULITIS & ART
\end{tabular}}

A. Hočevar ${ }^{1,2}$, V. Jurčić ${ }^{3}$, M. Tomsic ${ }^{1,2}$, Z. Rotar ${ }^{1,2} .{ }^{1}$ University Medical Centre Ljubljana, Department of Rheumatology, Ljubljana, Slovenia;

${ }^{2}$ Medical Faculty, University of Ljubljana, Internal Medicine, Ljubljana, Slovenia; ${ }^{3}$ Medical Faculty, University of Ljubljana, Institute of Pathology, Ljubljana, Slovenia

Background: Arthritis is one of the main clinical features of IgA vasculitis (IgAV). Joint involvement represents the second most common manifestation in childhood IgAV with the predilection for the knees and ankles.

Objectives: We aimed to describe the characteristics of arthritis in adult IgAV cohort.

Methods: We analysed medical records of histologically proven adult IgAV cases, diagnosed between January 2010 and December 2020 at our secondary/ 